\title{
As masmorras capixabas e o ronco surdo da batalha
}

The espírito santo dungeons and the deaf rumble of the battle

Las mazmorras capixabas y el ronco sordo de la batalla

\section{Ana Cristina Scopel}

Universidade Federal do Espírito Santo, Vitória, ES, Brasil.

Gilead Marchezi Tavares

Universidade Federal do Espírito Santo, Vitória, ES, Brasil.

\section{Resumo}

Partindo da publicização nacional da realidade prisional capixaba, este artigo visa discutir a função política da prisão, na tentativa de evidenciar transformações sócio-históricas que possibilitam a manutenção do estado de dominação presente nas prisões brasileiras e, ao mesmo tempo, as insistentes expressões de combate à tal lógica, encampadas por movimentos dos direitos humanos. Trata-se de pesquisa documental que se utilizou do Relatório do Conectas Direitos Humanos de 2010 sobre a situação prisional do Espírito Santo como dispositivo de análise da questão prisional brasileira. Dessa forma, a análise foi realizada a partir do cruzamento do referido relatório com documentos oficiais de governo e a bibliografia sobre o tema. Constata-se que as prisões funcionam como dispositivos do biopoder contemporâneo que tem como uma de suas facetas a produção de vida zoé, insacrificável e matável. Por seu turno, as práticas de liberdade se apresentam cotidianamente nos movimentos sociais, subvertendo a lógica do medo encampada no estado de dominação.

Palavras chaves: Prisão, Poder, Direitos Humanos.

\begin{abstract}
Having as a departing point the national publishment of the carceral reality of the Espírito Santo State, this article intends to discuss the political function of the prison, with the attempt to evidence social and historical changes that enable the maintenance of the state of domination that exists in Brazilian prisons and, at once, the insistent combat manifestations against such logic, adopted by human rights movements. It is documentary research that was used the Conectas Human Rights Report from 2010 about the carceral situation of Espírito Santo as a device for analyzing the Brazilian prison issue. Thus, the analysis was
\end{abstract}


performed from crossing the Report with official government documents and literature on the subject. It is found that prisons work as contemporary biopower devices which has as one of its aspects the production of zoe life, unexpendable and killable. In its turn, liberty practices daily present themselves in social movements, subverting the logic of the fear adopted in the state of domination.

Key-words: Prison, Power, Human Rights.

\section{Resumen}

A partir de la revelación pública a nivel nacional de la realidad carcelaria capixaba, este artículo pretende discutir la función política de una cárcel, en la tentativa de poner en evidencia transformaciones socio-históricas que hacen posible el mantenimiento del estado de dominación existente en las cárceles brasileñas y al mismo tiempo, las insistentes expresiones de combate a dicha lógica, encampanadas por asociaciones de derechos humanos. Se trata de una investigación documental que se ha utilizado del Informe de Conectas Direitos Humanos de 2010 sobre la situación carcelaria del Estado de Espirito Santo como un dispositivo para analizar el tema de la prisión brasileña. Por lo tanto, el análisis se realizó a partir de cruzar el Informe con los documentos oficiales del gobierno y de la literatura sobre el tema. Se viene constatando que las cárceles funcionan como dispositivos de bio-poder contemporáneo que tienen la producción de vida zóe, insacrificable y matable, como alguna de sus facetas. A la vez, las prácticas de libertad se presentan de manera cotidiana en los movimientos sociales, subvirtiendo la lógica del miedo encampanada en el estado de dominación.

Palabras clave: Cárcel, Poder, Derechos Humanos.

\section{Introdução}

No ano de 2010, o Estado do Espírito Santo tornou-se visível para o mundo como o lugar das masmorras medievais. Publicizado em jornal de circulação nacional (O GLOBO, 07/03/2010), a partir de denúncia pública gerada por Petição, elaborada pelo Conectas
Direitos Humanos (2010), junto ao Supremo Tribunal Federal solicitando a intervenção Federal no Estado do Espírito Santo, este governo ganhou o mundo ao ser alvo de um painel de discussão articulado à Reunião do Conselho de Direitos Humanos das Nações 
Unidas, ocorrido em Genebra, em 15 de março de 2010.

A Petição baseou-se em relatório (Conectas direitos humanos, 2010), incluindo fotos enauzeantes, da realidade prisional do referido Estado, há muito observada por organismos nãogovernamentais. Torturas, maus tratos e mortes violentas sem que qualquer ação apurativa ou atitude preventiva ou mesmo de indignação por parte do poder público fosse levada a cabo. Ao contrário, pode-se afirmar que o Governo do Estado do Espírito Santo historicamente se presta a minar ações de Movimentos Sociais em prol dos Direitos Humanos ao que se refere à situação dos presídios (Conselho estadual dos direitos humanos, 2010). Tal fato deve ser situado no contexto político que propicia as violações de direitos. O Presidente do Conselho Estadual dos Direitos Humanos, Bruno Alves de Souza Toledo, em seu momento de fala na Organização das Nações Unidas (ONU), apresenta a relação entre as violações de direitos no Sistema Prisional e o desenvolvimento do crime organizado nos poderes públicos capixabas:

Com os poderes públicos dominados pelo crime, o sistema prisional, por sua vez, passou a integrar a rede de corrupção, seja para concessão de benefícios ilegais, seja para utilização de presos para a prática criminosa a serviço do crime organizado. Este foi, inclusive, um dos motivos que aparecem nas investigações da morte do Juiz Alexandre Martins, que denunciou o esquema de corrupção na Vara de Execução Penal da Capital (Toledo, 2010, p. 18).

Focando-nos na realidade das "masmorras capixabas", chamamos a atenção para o relatório do Conectas no que ele traz de "chocante" em relação ao modo de funcionamento moderno das penalidades. Sabemos que as punições em forma de suplícios foram "substituídas", via de regra, pela privação de liberdade especialmente porque os primeiros passaram a não ser tolerados pela população. Então, como analisarmos a relativa inércia da população capixaba e do poder público no que diz respeito às fotos medievais de enforcamento e esquartejamentos trazidas a público pelo relatório?

Este artigo visa discutir a função política da prisão, na tentativa de evidenciar transformações sócio-históricas que possibilitam a manutenção do "estado de dominação" presente nas prisões brasileiras e, ao mesmo tempo, as insistentes expressões de combate à tal lógica, encampadas, por exemplo, pelos 
movimentos socais em prol dos direitos humanos.

A pesquisa, de natureza documental, se baseou no Relatório do Conectas Direitos Humanos (2010), em relatórios do Sistema Integrado de Informações Penitenciárias do Ministério da Justiça e em revisão bibliográfica sobre o tema. O Relatório do Conectas Direitos Humanos foi utilizado como documento central, disparador da análise aqui proposta, e, portanto, é pensado como dispositivo de análise da questão prisional brasileira. As discussões que se seguem são resultado da análise produzida pelo cruzamento do referido Relatório com os documentos oficiais do Governo Brasileiro e a revisão bibliográfica sobre o tema.

\section{2 - Para que prisões?}

Segundo Foucault (2008), as primeiras formas de castigo de um "fora da lei" foram os suplícios: torturas cometidas sobre o corpo em praça pública para a exibição da dor, sofrimento e humilhação do condenado. Foi somente no fím do século XVIII e começo do XIX que os suplícios, como penalidade, começaram a se extinguir.

Saem de cena os suplícios sobre a carne e as punições passam a ser exercidas sobre a alma do criminoso, visto que o castigo destinado aos fora da lei passa a se inscrever, profundamente, sobre o coração, o intelecto, a vontade, as disposições. Segundo essa nova forma de penalidade, o corpo é colocado num sistema de coação e de privação, de obrigações e de interdições. O castigo passou de uma arte das sensações insuportáveis a uma economia dos direitos suspensos.

O surgimento da prisão pode ser pensado como reflexo da crise das sociedades de soberania e ascensão das sociedades disciplinares. Para as primeiras, o poder se exercia, antes de tudo, segundo Foucault (2010c), como direito de apreensão das coisas, do tempo, dos corpos e, finalmente, da vida; seu exercício culminava com o privilégio de se apoderar da vida para suprimi-la. Nas sociedades disciplinares surgem os mecanismos voltados à incitação da vida, ao seu controle, vigilância, um poder destinado a produzir forças, a fazê-las crescer e a ordená-las mais do que barrá-las, dobrá-las ou destruí-las.

O nascimento das prisões, certamente, marca o início de - e afirma novas formas da humanidade se relacionar. Um aparelho disciplinar exemplar (assim como o é a prisão) deve agir sobre o homem de forma mais exaustiva possível, tomando 
para si todos os aspectos da vida e do corpo do indivíduo: "seu treinamento físico, sua aptidão para o trabalho, seu comportamento cotidiano, sua atitude moral, suas disposições [...]. Sua ação sobre o indivíduo deve ser ininterrupta: disciplina incessante" (Foucault, 2008, p. 198).

Com o "advento" das prisões, aquele que anteriormente era reconhecido como adversário do soberano, passa a integrar o papel de inimigo social e se transforma em sujeito desviado, que carrega consigo o perigo múltiplo da desordem, do crime, da loucura. Ainda de acordo com Foucault (2008), a prisão pré-existe à sua utilização sistemática nas leis penais. Ela surgiu fora dos aparelhos judiciários, na realização de processos que intencionavam repartir os indivíduos, fixá-los, distribuí-los, esquadrinhá-los, classificá-los e deles se retirar o máximo de tempo e de forças. Uma aparelhagem capaz de tornar os indivíduos dóceis e úteis ao sistema de produção através de um trabalho preciso sobre seu corpo.

Mas, oficialmente, a que se propõe a prisão? Thompson (1980) traça interessantes questionamentos em sua obra $A$ questão penitenciária e nos responde e problematiza a que se pretendem as prisões. De acordo com o autor, são três as finalidades ditas oficiais: I) punição retributiva do mal causado à sociedade pelo infrator; II) prevenção da prática de novas infrações, usando-se para tanto da intimidação do condenado e de pessoas potencialmente criminosas; III) regeneração do condenado, no sentido de transformá-lo de criminoso em sujeito não-criminoso. A meta de reabilitação, segundo Thompson (1980), passa a merecer especial ênfase no século XIX e pretende-se a cura, a regeneração, a recuperação, a readaptação, a ressocialização e a reeducação do encarcerado.

Foucault (2009), ao traçar o surgimento das prisões, relata a prática da chamada lettre-de-cachet instituída na França no século XVIII, apresentando-a como instrumento de punição (condicionado ao decreto do rei) solicitada por qualquer membro da comunidade e direcionada a uma pessoa ou grupo. Ao decretar uma lettre-decachet, o rei poderia ordenar a prisão daquele considerado perigoso ou que coloca em risco as boas condutas religiosas, a moralidade ou aquele que é desordeiro em seu trabalho. A duração da pena de prisão não era delimitada e o sujeito estaria à mercê do julgamento daquele que solicitou sua punição (a comunidade, a igreja, o empregador ou um pai que tentara casar sua filha etc.). A pena de prisão estava terminada quando o solicitante da lettre-de-cachet 
entendia que o condenado já havia se corrigido de sua falta.

Portanto, vemos que a prática de prisão enquanto possibilidade de cura, regeneração, recuperação, readaptação, ressocialização e reeducação do encarcerado tem início com as lettre-de-cachet na França no século XVIII, como assinala Foucault (2009).

Trata-se aqui, de refletirmos sobre a ideia do encarceramento como possibilidade de cura e de correção do sujeito. Foucault (2005) destaca em claras palavras que a prisão está longe de transformar os criminosos em "gente honesta", servindo apenas para fabricar novos criminosos ou afundá-los ainda mais na criminalidade. Oportunamente nos fazemos valer da colocação encontrada em Thompson (1980), para problematizarmos a penalidade moderna por meio da punição e da correção: "Para punir um homem retribuitivamente é preciso injuriá-lo. Para reformá-lo, é preciso melhorá-lo. E os homens não são melhoráveis através de injúrias" (p. 06).

Foucault (2008) destaca:

A criminalidade não nasce nas margens e por efeito de exílios sucessivos, mas graças a inserções cada vez mais rigorosas, debaixo de vigilâncias cada vez mais insistentes, por uma acumulação de coerções disciplinares.
Em resumo, o arquipélago carcerário realiza, nas profundezas do corpo social, a formação da delinquência a partir das ilegalidades sutis, o ressarcimento destas por aquela e a implantação de uma criminalidade especificada (p. 249).

Dessa forma, os objetivos/metas "re" (regeneração, recuperação, readaptação, ressocialização e reeducação do encarcerado) do sistema prisional não ultrapassam a categoria de ilusões. Ilusões amargas que adocicam (buscam legitimar) o apelo cada vez maior pela punição, pela privação de liberdade que se aplica a uma parcela da população, considerada como verdadeira ameaça ao bem estar social. Segundo Batista (2009), população essa que sempre foi a dos dessocializados, desintegrados, desclassificados. Assim, em seus objetivos explícitos (as metas "re"), o sistema prisional tem se mostrado, há muito, fracassado. Entretanto, tem funcionado muito bem ao se propor controlar, arrumar, diferenciar e selecionar os ilegalismos populares e os ilegais. Dessa forma, Batista (2009) atenta-nos para o fato de que o sistema penal constitui-se em armadilha: os discursos orientados através dos objetivos/metas "re" deslocam-nos para uma malha fina, às vezes sutil, em que são tecidas medidas de contenção e controle social 
elaboradas com critérios bem explícitos quanto à sua seletividade.

Portanto, a penalidade instalada a partir do século XIX instaura-se sob novo aspecto, voltando-se mais incisivamente para o controle e reforma psicológica e moral dos comportamentos e atitudes dos sujeitos criminosos (Foucault, 2009). Sob essa nova forma de punição vislumbra-se o controle dos sujeitos e a vigilância de seus comportamentos, de modo que a penalização não mais incide sobre o crime, mas pune-se o criminoso por aquilo que ele pode vir a fazer, ao que é capaz de fazer ou aquilo que está "sujeito" a fazer. Uma nova forma de punir, portanto, se estabelece para aqueles que contrariaram a lei. Esta passa a atuar ao nível das virtualidades do homem e faz emergir, ao final do século XIX, a noção de periculosidade:

A noção de periculosidade significa que o indivíduo deve ser considerado pela sociedade ao nível de suas virtualidades e não ao nível de seus atos; não ao nível das infrações efetivas a uma lei efetiva, mas das virtualidades de comportamento que elas representam (Foucault, 2009, p. 85).

Com a incorporação do poder disciplinar ao biopoder, as ciências ganham relevante papel no que diz respeito às práticas judiciárias. Essa noção de periculosidade e as ações punitivas constituem-se a partir de uma série de saberes ditos científicos, tais como a psiquiatria, a psicologia, a sociologia etc., conhecimentos que passam a orientar o judiciário, legitimando suas intervenções sociais.

De acordo com Foucault (1999), no biopoder tem-se a inversão da máxima colocada sobre as práticas de soberania, em que cabia ao soberano fazer morrer ou deixar viver. $\mathrm{O}$ direito de vida e poder sobre a morte estavam sob domínios do poder soberano e com o surgimento do biopoder ocorre a inversão dessa lógica: há a pretensão de se alongar a vida, de otimizá-la, favorecendo os processos de longevidade, importando agora o fazer viver e o deixar morrer. De acordo com Foucault (1999), é a vida que entra em cena, vida enquanto espécie e a ela se aplicam normas e regulamentações, com a finalidade de se estabelecer um controle não somente sobre o indivíduo, mas também sobre a população.

Mas se atualmente vivemos em uma sociedade voltada ao prolongamento da vida, à longevidade humana e à incitação da vida, esses preceitos permanecem dentro de realidades tais como os estabelecimentos prisionais? É verdadeira a máxima fazer 
viver dentro dessas instituições de sequestro? ${ }^{1}$ Ao que parece, a realidade das penitenciárias brasileiras se enquadram menos no fazer viver e mais no deixar morrer. Ou será que podemos falar de um fazer morrer?

O poder soberano, formulado como direito de vida e de morte, não é extinto com o advento do poder disciplinar e do biopoder. Eles coexistem nas mais diversas práticas sociais, se manifestam sob mecanismos diversos e se atualizam a todo o instante em diferentes dispositivos ${ }^{2}$ de poder. Portanto, dentro das unidades prisionais vemos o poder soberano ("direito de apreensão das coisas, do tempo, dos corpos e, finalmente, da vida; culminava com o privilégio de se apoderar da vida para suprimi-la”, Foucault, 2010c) atualizando-se em diferentes práticas dessa instituição, fazendo-nos pensar na existência de um fazer morrer ou deixar viver (direito do soberano sobre seus súditos) que, dessa forma, não está distante de nossa atual realidade biopolítica.

Acreditamos que as constatações do Conectas Direitos Humanos (2010) não deixam dúvidas quanto à forte presença do fazer morrer nas prisões brasileiras e, em especial, no sistema prisional capixaba.
A realidade retratada nos diversos meios de comunicação vem confirmar constatações de Wacquant (2001) quando visitou algumas penitenciárias brasileiras:

É o estado apavorante das prisões do país, que se parecem mais com campos de concentração para pobres, ou com empresas públicas de depósito industrial dos dejetos sociais, do que com instituições judiciárias servindo para alguma função penalógica dissuasão, neutralização ou reinserção (p. 11). Nesse sentido, Lemos (2007) aponta que onde se percebem a ausência do respeito pela vida e pela integridade física e moral do sujeito, a ausência de condições mínimas para uma existência digna, o uso do poder de forma ilimitado, a liberdade fragilizada e uma autonomia inexistente - nessa dura realidade encontrada nas prisões onde muitos dos direitos fundamentais não são reconhecidos e minimamente assegurados não há espaço para a dignidade da pessoa e esta poderá servir como mero objeto de arbítrio e injustiças.

O fazer morrer, portanto, se faz presente quando aos internos são negados direitos mínimos de dignidade humana, tais como acesso à saúde, educação, esporte, trabalho etc. A dura realidade a que estão submetidos - superpopulação carcerária, péssimas condições de higiene e de 
alimentação, estando entregues a todo tipo de violência - nos faz perceber e analisar quem de verdade está inscrito à máxima do fazer viver.

\section{3 - As prisões da vida nua}

Segundo Agamben (2010), os gregos não possuíam um único termo para definir o que nós entendemos pela palavra vida. Com semântica e morfologia distintas, referiam-se a Zoé como o simples fato de viver comum a todos os seres vivos (animais, homens ou deuses), enquanto Bios indicava a forma ou maneira de viver própria de um indivíduo ou grupo.

Por zoé, entende-se uma vida nãopolitizada, uma simples vida natural, que no mundo clássico era excluída da pólis e estaria confinada à mera vida reprodutiva. A vida reduzida à esfera zoé faz com que os corpos sejam "matáveis", sem que tais mortes constituam a noção de homicídios ou crimes, pois trata-se de corpos distantes de toda relevância política social. A vida, nessa dimensão, está reduzida à sobrevida puramente biológica.

A realidade do sistema prisional brasileiro, infinitas vezes veiculada pela mídia nacional e internacional, sem tirar nem por exageros, retrata a subjugação da vida ao seu aspecto mais cru e mais dissecado: a vida nua. Vida tratada como fato, como puro fato da existência biológica do ser. Vida colocada como fato comum a todos os seres vivos: vida zoé.

Ocupando o lugar de "fato", a vida se torna objeto "capturável" pelo poder dominante que a isola da compreensão da vida enquanto bios, enquanto "formas" ou maneiras de viver peculiares a determinado sujeito ou grupo. A vida como mero fato biológico, vida nua, zoé, está submetida ao poder soberano e ao seu arbítrio, colocada a um só tempo como objeto de exclusão e inclusão, como expressão do direito de morte e poder sobre a vida. Assim, a existência das concepções de Homo Sacer e a Vida Nua tornam possíveis e executáveis as relações de soberania, visto que o poder soberano opera sobre e constitui o Homo Sacer enquanto tal.

A figura do Homo Sacer, segundo Agamben (2010), é a figura do direito romano arcaico, cuja especificidade está no fato de sua morte não constituir qualquer tipo de penalidade (sua vida é tratada a partir da noção de zoé) e no veto de seu sacrifício. A vida do Homo Sacer está situada no cruzamento entre uma matabilidade e uma insacrificabilidade. Esta última configura-se no sentido de que a violência cometida contra essa vida não constitui sacrilégio, 
visto que não se trata de uma vida digna de ser consagrada aos deuses. Logo, a vida do Homo Sacer é duplamente excluída, tanto do direito humano (sua morte não representa crime), quanto do direito divino (este não é passível de sacrifício), tanto do âmbito profano quanto do religioso.

A noção de Homo Sacer, que classifica o indivíduo como uma vida matável, sem que sua morte agregue prejuízos jurídicos ou qualquer outra penalidade ao seu assassino, visto que se trata de uma pura vida biológica, sem valor político ou social, é bastante atual e extremamente visível no contexto prisional.

Ainda de acordo com o autor, a decisão soberana, que suspende a lei no estado de exceção, é a esfera-limite do agir humano que implica, em seu funcionamento, a produção da vida nua. Se a vida do Homo Sacer é insacrificável e matável por qualquer um, a dimensão da vida nua constitui o referente ao Homo Sacer na violência soberana.

Na biopolítica moderna, soberano é aquele que decide sobre o valor ou sobre o desvalor da vida enquanto tal. A integração entre a medicina e a política, uma das características essenciais da biopolítica moderna, implica que a decisão soberana sobre a vida se desloque de motivações e âmbitos estritamente políticos para um terreno mais ambíguo, no qual médico e soberano parecem trocar de papéis. No espaço prisional, como aliados do sistema disciplinar e biopolítico, estão presentes, além da figura do médico, o psicólogo e o assistente social, assumindo posições soberanas sobre os reclusos, uma vez que o futuro dessas vidas torna-se dependente, perante a justiça, de laudos e relatórios sociais e psicológicos. A exigência e a relevância desses laudos parecem corroborar com aquilo que Agamben (2010) traz como característica essencial da biopolítica moderna, qual seja "a necessidade de redefinir continuamente o limiar que articula e separa aquilo que está dentro daquilo que está fora, bios e zoé, vida nua e existência política" (p. 127).

As constantes notícias de assassinatos entre os internos, de bárbaros crimes e torturas cometidos por aqueles que deveriam custodiar e cuidar, representantes aqui do Estado, as frequentes rebeliões provocadas em protesto pelos índices inacreditáveis de superlotação prisional, nos faz questionar: Em um país dito democrático como o Brasil, como essas mortes tornam-se aceitas por sua população? Por que os crimes cometidos contra a massa carcerária não geram manifestações populares, ao 
contrário, permanecem em estado de inércia até mesmo os representantes legais do Direito e os líderes políticos?

Em sua obra Homo Sacer, ao retratar a condição das VP (Versuchepersonen, cobaias humanas das experimentações nazistas alocadas nos campos de concentração), Agamben (2010) questiona por que as brutais experiências com cobaias humanas, também acontecidas em estados americanos, com cidadãos americanos condenados à morte, tornaram-se possíveis, sendo os EUA um país democrático.

O autor responde:

A única resposta possível é a de que tenha sido decisiva, em ambos os casos [no estado democrático americano e no estado de exceção nazista], a particular condição das VP (condenados à morte ou detentos em um campo de concentração, o ingresso no qual significava a definitiva exclusão da comunidade política). Justamente porque privados de quase todos os direitos $\mathrm{e}$ expectativas que costumamos atribuir à existência humana e, todavia, biologicamente ainda vivos, eles vinham a situar-se em uma zona-limite entre a vida e a morte, entre o interno e o externo, na qual não eram mais que vida nua. Condenados à morte e habitantes do campo, são, portanto, de algum modo inconscientemente assemelhados a homines sacri, a uma vida que pode ser morta sem que se cometa homicídio (p. 155).
Encontramos aqui um ponto de convergência entre os americanos condenados à morte, os desnacionalizados entregues às "peripécias" nos campos nazistas e os internos do sistema prisional brasileiro. Estar recluso, sob aquilo que poderíamos chamar de primitivas condições de existência humana, desvinculado/excluído do resto da comunidade política e privado de quase todos os direitos e expectativas atribuídas à condição humana, faz do presidiário um ser habitante da mais pura condição de vida nua, de homo sacer, de ser matável e, portanto, irrelevante seria sua sobrevivência para a sociedade.

Foucault (1999) remete-nos à noção de Racismo de Estado $^{3}$ para abordar semelhantes questões. Na emergência do biopoder, diante das funções de prolongar a vida, sua duração, suas possibilidades e multiplicidades, desviando seus acidentes ou então compensando suas deficiências, como era (e ainda é) possível para um poder político assumir a postura de matar, de reclamar a morte, pedir a morte, mandar matar ou expor à morte?

A partir da concepção de raças humanas, surgem as distinções e hierarquias entre aquelas raças ditas superiores e as inferiores, as dominadoras e as dominadas, 
as evoluídas e as degeneradas. Frente à qualificação de certas raças e à forçosa desqualificação de outras, o racismo atua como mecanismo de corte, um corte entre aqueles que podem (devem) morrer e aqueles que devem, ou merecem, viver. $\mathrm{O}$ racismo moderno cumpre a função de defasar, no interior das populações, uns grupos em relação aos outros, fragmentar povos.

Quanto à defasagem de populações, podemos dizer que não se trata de algo natural, mas de um processo historicamente construído, algo que se produz nas malhas do tecido social. Muitos são os mecanismos que separam os "povos", a prisão está entre eles. Segundo Foucault (2010b), a prisão funciona como um dispositivo de segregação ao produzir o corte entre "os bons cidadãos" e os "bandidos", além de produzir e reforçar a noção de delinquência. E não só segrega os "bons cidadãos" dos "bandidos", como também recorta entre as camadas empobrecidas aqueles tidos como "pobre digno" e "pobre indigno".

É como se toda a valorização e toda a "politização da vida" implicasse necessariamente uma nova decisão sobre o limiar além do qual a vida cessa de ser politicamente relevante, é então somente "vida sacra", e como tal, pode ser impunemente eliminada. Toda sociedade fixa este limite, toda sociedade decide quais são seus homens sacros (Agamben, 2010, p. $135)$.

Para Foucault (1999), as noções de raça e de racismo são a condição de aceitabilidade que permite eliminar uma vida numa sociedade de normalização. A função “assassina” do Estado só pode ser assegurada desde que o Estado funcione no modo do biopoder, pelo racismo. Este representa a condição para que se possa exercer o velho direito soberano de causar a morte.

Os trechos que se seguem são do relatório/denúncia do Conectas Direitos Humanos (2010), que solicitou ao Supremo Tribunal Federal a intervenção federal em várias unidades prisionais e de internação para adolescentes em conflito com a lei do Estado do Espírito Santo. Esses fragmentos denunciam a presença, para a qual, muitas vezes, estamos de olhos vendados, do homo sacer, da vida nua e do racismo de Estado hoje.

\footnotetext{
Na unidade de internação de adolescentes UNIS - foi relatada a presença de adolescentes em dois contêineres, que ficavam expostos ao sol, submetidos à temperatura de até $50^{\circ} \mathrm{C}$, sem banheiro e sem água encanada. Os adolescentes eram
} 
obrigados a defecar e urinar dentro do próprio contêiner e, em um dos contêineres, os excrementos dos adolescentes ficavam acumulados como um córrego no canto sulcado do caixote. O cheiro era repulsivo. Alguns adolescentes vomitavam constantemente (Conectas direitos humanos, 2010).

\section{4 - A vida nua irrepresentável nos números oficiais}

A realidade do sistema penitenciário capixaba está "aberta" para toda a população. Encontramo-la estampada nas fotos de jornais, noticiada em sites, denunciada em blogs particulares e escancarada, quando em troca a notícia gera ibope, nos programas de TV. Não há, portanto, muita novidade nos números que apresentaremos a seguir. A tentativa é de problematizar exatamente aquilo que nos aparece como sendo banal.

De acordo com o Departamento Penitenciário Nacional (DEPEN), em junho de 2010, o Espírito Santo possuía uma população carcerária de 11.870 detentos. A capacidade para custodiar essas pessoas era de 8.928 vagas, totalizando um déficit de 2.942 vagas (Ministério da justiça, 2010).

Certamente não se trata de um déficit a ser ignorado. A superlotação dos presídios é fato inquestionavelmente gerador de muitos problemas entre os internos do sistema. Rebeliões, fugas, assassinatos brutais, lutas por um espaço nas celas, disputas por colchões e aquilo que cumpre a vez de cama, sem mencionar as condições degradantes de higiene e alimentação a que estão submetidos.

O InfoPen (Sistema Integrado de Informações Penitenciárias) é responsável por publicizar, através do site do Ministério da Justiça ${ }^{4}$, relatórios semestrais referentes às diversas características (números de vagas, de internos, grau de escolaridade, faixa etária, origem étnica etc.) da população carcerária e do sistema prisional brasileiro. Para cada um dos 27 Estados da Federação produz-se um relatório semestral. Nesse momento, interessa-nos o número de saídas do sistema penitenciário capixaba nos dois últimos relatórios gerados pelo InfoPen (referentes aos meses de julho a dezembro de 2009 e de janeiro a junho de 2010). Os relatórios de todos os Estados brasileiros apontam seis motivos para a saída dos internos do sistema prisional: a) Fuga; $b$ ) Abandono; c) Alvará de soltura/Hábeas Corpus; d) Remoção/ transferência; e) Indulto; $f$ ) Óbito (natural, criminal, suicídio e acidental).

No último semestre de 2009, assim como no primeiro semestre de 2010, o 
número referente às saídas do sistema penitenciário do Estado do Espírito Santo em decorrência de óbito, apresentado pelo InfoPen, foi de zero. Ao contrário das denúncias diárias feitas por jornais, canais de TV, Ong's, OSCIP's e pelo Conselho Estadual de Direitos Humanos, no Espírito Santo, no período de um ano (julho de 2009 a junho de 2010), não houve nenhum caso de óbito dentro de seu sistema prisional.

Apropriamo-nos, mais uma vez, de um fragmento da solicitação de intervenção federal nas unidades prisionais capixabas, oriunda do Conectas:

Acrescente-se que em 29 de setembro [de 2009] ocorreu mais um episódio desta tragédia anunciada: dois corpos foram encontrados na Casa de Custódia de Viana CASCUVI. Os presos Messias de Nazaré Chaves, de 25 anos, e Waldequir da Silva Pinto, de 21 anos, ao que tudo indica, foram espancados até a morte (Conectas direitos humanos, 2010).

Diante da dissonância dos dados, torna-se válida e necessária uma simples pergunta: o que essa postura de omissão de dados produz? Não intencionamos aqui apenas contestar as informações do InfoPen, apresentando provas de que suas estatísticas não estão de acordo com a realidade do Estado do Espírito Santo. Devemos, sobretudo, problematizar esses dados, ampliar nosso olhar para essa realidade, pensar o que isso produz, para que ou para quem essas estatísticas servem? Quais seus efeitos? O que elas estão produzindo no tecido social?

As vidas ceifadas no interior dos presídios capixabas, não transformadas em estatísticas e, portanto, não reconhecidas pelo Estado, compreenderiam ao Homo Sacer de hoje? Seriam elas aquelas vidas matáveis e insacrificáveis? Vida nua, zoé? Essas estatísticas apontariam para a existência dessa vida matável? Um assassinato que não constitui crime, já que não entra nem mesmo para os dados do Ministério da Justiça?

Cabe-nos ainda rever o chamado óbito por motivo natural no contexto carcerário. Até onde tais mortes (sabidas, mas não reveladas nas estatísticas citadas) podem ser consideradas naturais? Morre-se porque "assim quis" a natureza do corpo? Padece-se apenas seguindo o rumo natural da vida? $\mathrm{Ou}$ estariam essas vidas encarceradas sendo submetidas a condições que não as levariam para outro lugar senão à morte? Vidas nuas entregues à própria sorte? Deixa-se morrer, faz-se seu fim. 


\section{5 - O estado de dominação em nós e as práticas de liberdade}

Ao caminharmos na esteira do pensamento foucaultiano, torna-se imprescindível lançarmos mão de suas análises acerca das relações de poder. Não há, no pensamento de Foucault, uma fonte de emanação do poder - costumamos atribuir, inadequadamente, ao Estado o nascedouro desse poder -, assim como não se pode conceber a existência de dominados e dominadores. Há sim uma rede de micropoderes que se relacionam/articulam com o Estado e que atravessam toda a estrutura social. "O poder está em toda a parte; não porque englobe tudo e sim porque provém de todos os lugares" (Foucault, 2010d). Assim, as relações de poder são relações entre sujeitos entendidas como modos de ação que não atuam direta e imediatamente sobre os outros, mas sobre suas ações. São relações que visam conduzir condutas.

Entretanto, as relações de poder exigem que o outro (aquele sobre quem se exerce) seja reconhecido e mantido até o final como sujeito de ação, e também que se abra, frente à relação de poder, todo um campo de respostas, reações, efeitos, invenções possíveis. Foucault (2010a) destaca que é característica das relações de poder a mobilidade, a flexibilidade, a instabilidade e a reversibilidade. Essas relações só se configuram como relações de poder se nelas mesmas houver a presença de liberdade. Pelo menos certa forma de liberdade que permita ao sujeito criar estratégias que possam reverter a situação, escapar dela, ainda que "fugindo" ou mesmo "se matando". Assim, onde há relações de poder, há também liberdade.

Por outro lado, podemos pensar em casos em que as relações encontram-se extremamente fixas, imutáveis, rígidas e engessadas. A isso Foucault (2010a) denomina estados de dominação. Nesses estados, as relações se compõem e se perpetuam de forma assimétrica e a margem de liberdade se faz um tanto limitada, restrita a algumas poucas possibilidades de ação e resposta que dificilmente reverterão a situação vivida. Assim:

Quando um indivíduo ou um grupo social chega a bloquear um campo de relações de poder, a torná-las imóveis e fixas e a impedir qualquer reversibilidade do movimento - por instrumentos que tanto podem ser econômicos quanto políticos ou militares -, estamos diante do que se pode chamar de um estado de dominação. É lógico que, em tal estado, as práticas de liberdade não existem, existem apenas unilateralmente ou são 
extremamente restritas e limitadas (Foucault, 2010a, p. 266).

O dispositivo "prisão" faz funcionar uma lógica que não se encontra restrita ao lado de dentro de seus muros. Longe das muralhas e das guaritas, lá onde os homens se enxergam livres, os mecanismos de disciplinamento e controle, a velha toupeira e a habilidosa serpente ${ }^{5}$, se movimentam, circulam majestosas. Cavam seus buracos e serpenteiam por entre túneis que expelem a mesma espécie de "cola" que não atinge apenas aqueles seres "esquecidos" atrás de frias grades de ferro, mas que tratará de alcançar todos os corpos que circulam livremente. A cola especial que fixa lugares, saberes, valores, apenas age em intensidade maior ou menor, atingindo graus diferentes de ação. Mas não há quem esteja imune a ela.

As regras de funcionamento das famílias, da escola, da prisão, da fábrica, do hospital, se misturam e se pulverizam no campo social. Há uma diluição de seus "muros" ao mesmo tempo em que há um transbordamento de suas lógicas para outros setores (Machado, 2001, p. 74).

Desse modo, o dispositivo prisão, que atravessa toda a sociedade, busca a classificação de seus membros baseada na diferenciação entre obedientes e transgressores. O seguimento incondicional das leis, sua obediência irrestrita, constitui um assujeitamento sutil e quase silencioso que submete e desvia o desejo quanto mais o sujeito adere à lei. É por medo do castigo e esperança em receber recompensas que o sujeito submete-se a um poder que enfraquece, dilui e empobrece sua capacidade de sentir, pensar e agir livremente (Fuganti, 2011).

Essas relações microfísicas de poder que se estabelecem não apenas nas prisões, mas em toda a parte, atravessam os corpos, enfraquecem sua capacidade de sentir, pensar, falar e agir por ordem própria em benefício da produção de discursos que se querem legítimos, científicos, qualificados e autorizados a atribuir valores e a ditar formas/moldes de se viver (acerca do Bem/Mal). Nega-se a produção de multiplicidades, procura-se estancar as diferenças, instituem-se formas burocratizadas e engessadas de se viver.

Mas, a despeito das forças de dominação que produzem uma vida nua (vida zoé), encontramos, insistentes e resistentes no tecido social, as forças libertadoras que abrem caminho para a luta por direitos. Haja vista que este artigo só foi possível porque pessoas envolvidas em torno 
de um comum ${ }^{6}$ e munidas de uma coragem advinda da prática ética não se fizeram calar e subverteram a lógica do medo encampada pelo estado de dominação. As práticas de liberdade, práticas essas pensadas como condição para uma vida ética, fonte de elaborações de novas regras para o viver, regras não acabadas, não cristalizadas, mas sempre prontas a serem interrogadas e transformadas, se dão a cada novo encontro entre as pessoas, a cada nova tentativa de habitar uma zona de confiança.

Assim, compactuamos com as forças libertadoras, bradando e ouvindo o som da ética que avisa: Não está tudo dominado!

Nessa humanidade central e centralizada, efeito e instrumento de complexas relações de poder, corpos e forças submetidos por múltiplos dispositivos de 'encarceramento', objetos para discursos que são eles mesmos elementos dessa estratégia, temos que ouvir o ronco surdo da batalha (Foucault, 2008, p. 254).

\section{Notas:}

${ }^{1}$ Instituições de sequestro são entendidas e analisadas por Foucault (2009) como aquelas que objetivam fixar um indivíduo em um aparelho de normalização. A escola, a fábrica, a prisão e os hospitais têm por finalidade ligar o sujeito a um processo de produção, de formação ou de correção.

${ }^{2}$ Entendemos dispositivo como uma rede de relações que podem ser estabelecidas entre elementos heterogêneos: discursos, arquitetura, regramentos, leis, medidas administrativas, enunciados científicos, proposições filosóficas, morais, filantrópicas, o dito e o não dito (Castro, 2009a). Trata-se de uma formação que faz funcionar, que coloca em operação uma instituição garantindo a manutenção do instituído, ou que, por outro lado, serve à transformação, aos movimentos instituintes. Desse modo, o dispositivo responde a uma urgência, tendo uma função estratégica.

3 Os Racismos de Estado ou racismo moderno surge como uma estratégia global do Estado, uma estratégia que a sociedade exerce sobre si mesma em termos de purificação permanente e normalização social (CASTRO, 2009b).

${ }^{4}$ Ver: http://www.infopen.gov.br/

5 Alusão ao texto de Deleuze Post Scriptum, publicado em Conversações, 1992.

${ }^{6} \mathrm{O}$ comum aqui é pensado de acordo com Hardt e Negri (2005) ao apostarem na potência da multidão: "[ [...] o comum assinala uma nova forma de soberania, uma soberania democrática (ou, mais precisamente, uma forma de organização 
social que desloca a soberania) na qual as singularidades sociais controlam através de sua própria atividade biopolítica aqueles bens e serviços que permitem a reprodução da própria multidão" (p. 268). A multidão diz respeito a "[...] força informe de vida, e neste sentido um elemento do ser social, constantemente voltado para a plenitude da vida" (p. 251).

\section{Referências}

Agamben, G. (2010). Homo sacer: o poder soberano e a vida nua. (2a ed.). Belo Horizonte: Editora UFMG Humanitas.

Batista, V. M. (2009). Adeus às ilusões "re". Em: C. M. B. Coimbra; L. S. M. Ayres; M. L. Nascimento (Orgs.), PIVETES: encontros entre a psicologia e o judiciário (pp.195-199). Curitiba: Juruá.

Castro, E. (2009a). Dispositivo. Em: Vocabulário de Foucault - um percurso pelos seus temas, conceitos e autores. (pp.123-124). Belo Horizonte: Autêntica.

Castro, E. (2009). Racismo. Em: Vocabulário de Foucault - um percurso pelos seus temas, conceitos e autores. (pp.376-378). Belo Horizonte: Autêntica.

Conectas Direitos Humanos (2009). Petição junto ao Supremo Tribunal Federal solicitando a intervenção Federal no Estado do Espírito Santo. Recuperado em 06 de maio, 2010, de http://www.estadao.com.br/especiais/2

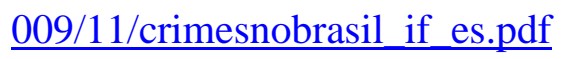

Conselho Estadual Dos Direitos Humanos Do Espírito Santo. (2010). 15 anos em revista. Recuperado em 05 de janeiro, 2011, de http://webcache.googleusercontent.co $\underline{\mathrm{m} / \text { search?q=cache:http://www.dhnet.o }}$ rg.br/dados/revistas/a_pdf/cedh_es_rev ista_direitos_humanos.pdf

Foucault, M. (1999). Aula de 17 de Março de 1976. Em: Em defesa da sociedade: curso no Collège de France (M. E. Galvão, Trad., pp. 285-315). São Paulo: Martins Fontes.

Foucault, M. (2005). Sobre a prisão. Em: Microfísica do poder. (pp. 73-81). Rio de Janeiro: Graal.

Foucault, M. (2008). Vigiar e punir: nascimento da prisão. (35a ed.) Petrópolis, RJ: Vozes.

Foucault, M. (2009). Conferência IV. A verdade e as formas jurídicas. (3a ed., 
pp. 79-102). Rio de Janeiro: NAU Editora.

Foucault, M. (2010a). A ética do cuidado de si como prática de liberdade. Em: M. B. da Motta (Org). Ditos e escritos V: ética, sexualidade e política. (2a ed., pp. 264-287). Rio de Janeiro: Forense Universitária.

Foucault, M. (2010b). A prisão vista por um filósofo francês. Em: M. B. da Motta (Org). Ditos e Escritos IV: estratégia, poder-saber. (2a ed., pp. 152-158). Rio de Janeiro: Forense Universitária.

Foucault, M. (2010c). Direito de morte e poder sobre a vida. Em: História da sexualidade I: a vontade do saber. (pp. 145-174). Rio de Janeiro: Graal.

Foucault, M. (2010d). Método. Em: História da sexualidade I: a vontade do saber. (pp.102-113). Rio de Janeiro: Graal.

Fuganti, L. (2011). A ética como potência e a moral como servidão. Recuperado em 14 de dezembro, 2011, de http://escolanomade.org/pensadorestextos-e-videos/fuganti-luiz/eticacomo-potencia-e-moral-como-servidao

Grupo De Monitoramento Integrado. (2011).

Violações de Direitos Humanos no Sistema Prisional do Espírito Santo Atuação da Sociedade Civil. Recuperado em 10 de janeiro, 2012, de http://global.org.br/wpcontent/uploads/ 2011/06/SistemaPrisionalES_2011.pdf

Hardt, M., \& Negri, A. (2005). Rastros da multidão. Em: Multidão. (pp. 247290).Rio de Janeiro: Record.

Lemos, C. E. R. (2007). A dignidade humana e as prisões capixabas. Vila Velha, ES: Univila.

Machado, L. A. D. (2001). Ética: exercícios de resistência em meio à indiferença. Em: H. Novo; A. Nobre; L. de Souza (Orgs.). Ética, Cidadania e Participação: debates no campo da Psicologia. (Vol. 1, pp. 71-80). Vitória: EDUFES.Ministério Da Justiça. (2010). Departamento Penitenciário Nacional. Relatórios estatísticos - analíticos do sistema prisional de cada estado da federação. Recuperado em 28 de outubro, 2010, de

http://portal.mj.gov.br/data/Pages/MJD 574E9CEITEMIDC37B2AE94C68400 68B1624D28407509CPTBRNN.htm

O Globo. (2010). As masmorras de Hartung aparecerão na ONU. Recuperado em 10 de março, 2010, de http://oglobo.globo.com/pais/noblat/po sts/2010/03/07/as-masmorras-de- 


\section{Polis e Psique, Vol.2, n.1, 2012 Página | 98}

hartung-aparecerao-na-onu-

E-mail: gilead.dindin@ig.com.br

$\underline{272212 . a s p}$

Thompson, A. (1980). A questão penitenciária. ( $2 \mathrm{a}$ ed.). Rio de Janeiro: Forense.

Toledo, B. A. S. (2010). O CEDH fala na ONU. Em: Conselho Estadual Dos Direitos Humanos Do Espírito Santo. 15 anos em revista. Recuperado em 05 de janeiro, 2011, de http://webcache.googleusercontent.co m/search?q=cache:http://www.dhnet.o rg.br/dados/revistas/a_pdf/cedh_es_rev ista_direitos_humanos.pdf

Wacquant, L. As prisões da miséria. (2001).

Rio de Janeiro: Zahar.

$\overline{\text { Ana Cristina Scopel Psicóloga, mestranda }}$ no Programa de Pós-Graduação em Psicologia Institucional da Universidade Federal do Espírito Santo. Psicóloga do Centro de Referência Especializado de Assistência Social (CREAS) do município de Linhares/ES.

E-mail: anacscopel@gmail.com

Gilead Marchezi Tavares Psicóloga, doutora em Psicologia, professora adjunta do Departamento de Psicologia e do Programa de Pós-Graduação em Psicologia Institucional da Universidade Federal do Espírito Santo. 